Supporting Information

\title{
Dual-Acting Tacrine-Human Cannabinoid Receptor 2 Ligands show Pronounced Neuroprotection in Vitro and Overadditive Effects in Vivo
}

\author{
Matthias Scheiner, Dominik Dolles, Sandra Gunesch, Matthias Hoffmann, Massimo Nabissi, Oliviero \\ Marinelli, Marina Naldi, Manuela Bartolini, Sabrina Petralla, Eleonora Poeta, Barbara Monti, Christina \\ Falkeis, Michael Vieth, Rangan Maitra, Harald Hübner, Peter Gmeiner, Tangui Maurice, and Michael \\ Decker*
}




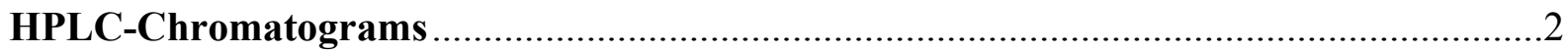

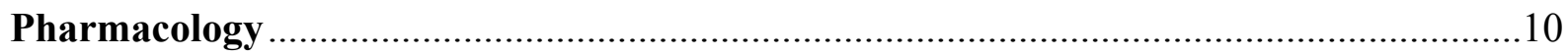



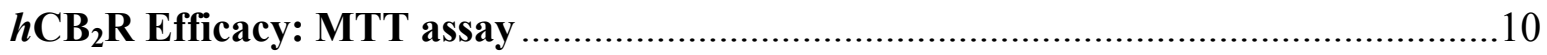

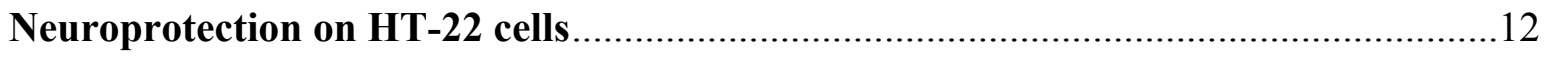

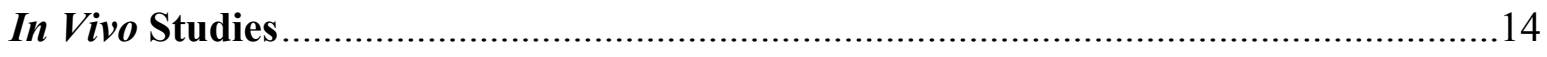

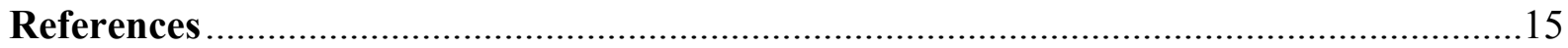




\section{HPLC-Chromatograms}

2-(4-Ethoxybenzyl)-N,N-diethyl-1-(2-((1,2,3,4-tetrahydroacridin-9-yl)amino)ethyl)-1H-

benzo[d]imidazole-5-carboxamide (3a).

Retention time: 7.90 min.; HPLC purity: 97\%

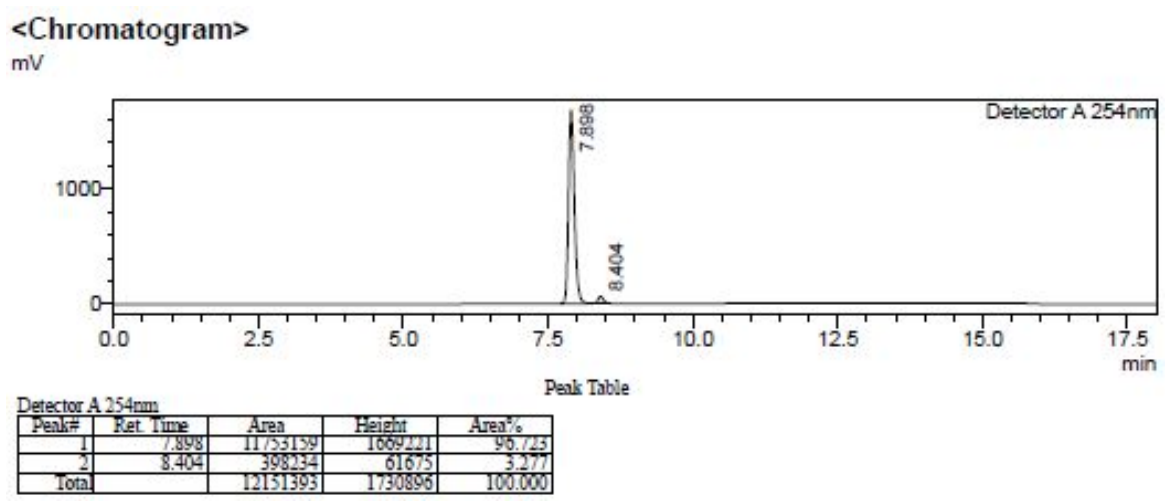

2-(4-Ethoxybenzyl)-N,N-diethyl-1-(3-((1,2,3,4-tetrahydroacridin-9-yl)amino)propyl)-1H-

benzo[d]imidazole-5-carboxamide (3b).

Retention time: 7.82 min.; HPLC purity: 98\%

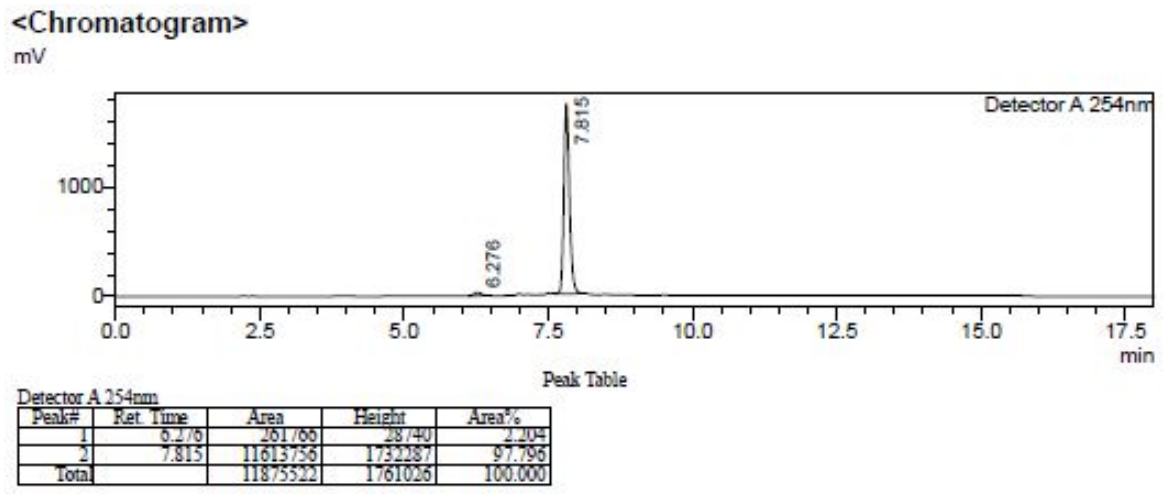


2-(4-ethoxybenzyl)-N,N-diethyl-1-(4-((1,2,3,4-tetrahydroacridin-9-yl)amino)butyl)-1Hbenzo[d]imidazole-5-carboxamide (3c).

Retention time: 7.92 min.; HPLC purity: 98\%

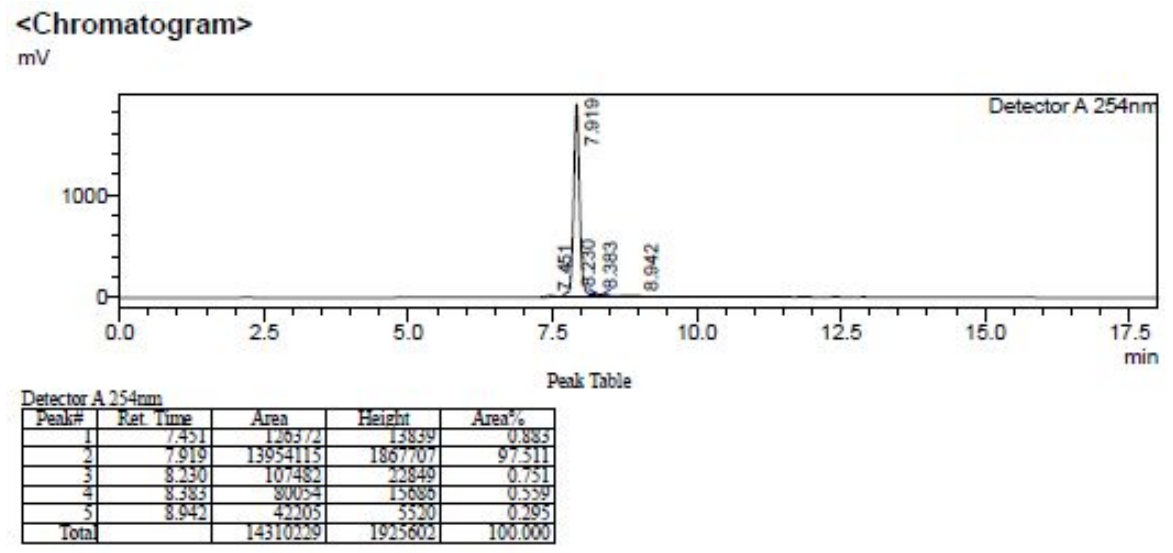

2-(4-Ethoxybenzyl)-N,N-diethyl-1-(5-((1,2,3,4-tetrahydroacridin-9-yl)amino)pentyl)-1Hbenzo[d]imidazole-5-carboxamide (3d).

Retention time: 8.07 min.; HPLC purity: 99\%

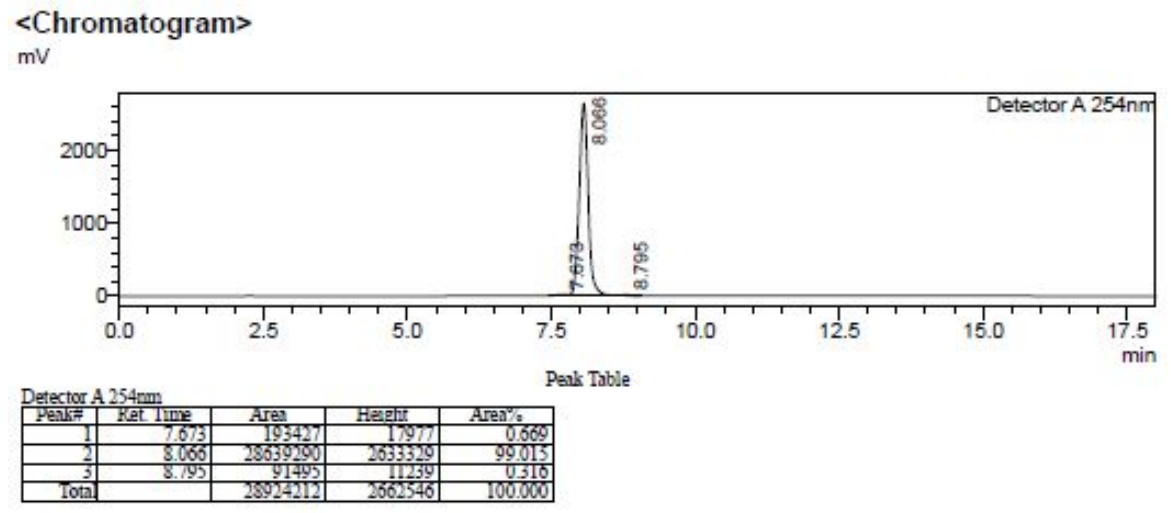


2-(4-Ethoxybenzyl)-N,N-diethyl-1-(6-((1,2,3,4-tetrahydroacridin-9-yl)amino)hexyl)-1H-

benzo[d]imidazole-5-carboxamide (3e).

Retention time: 8.27 min.; HPLC purity: 95\%

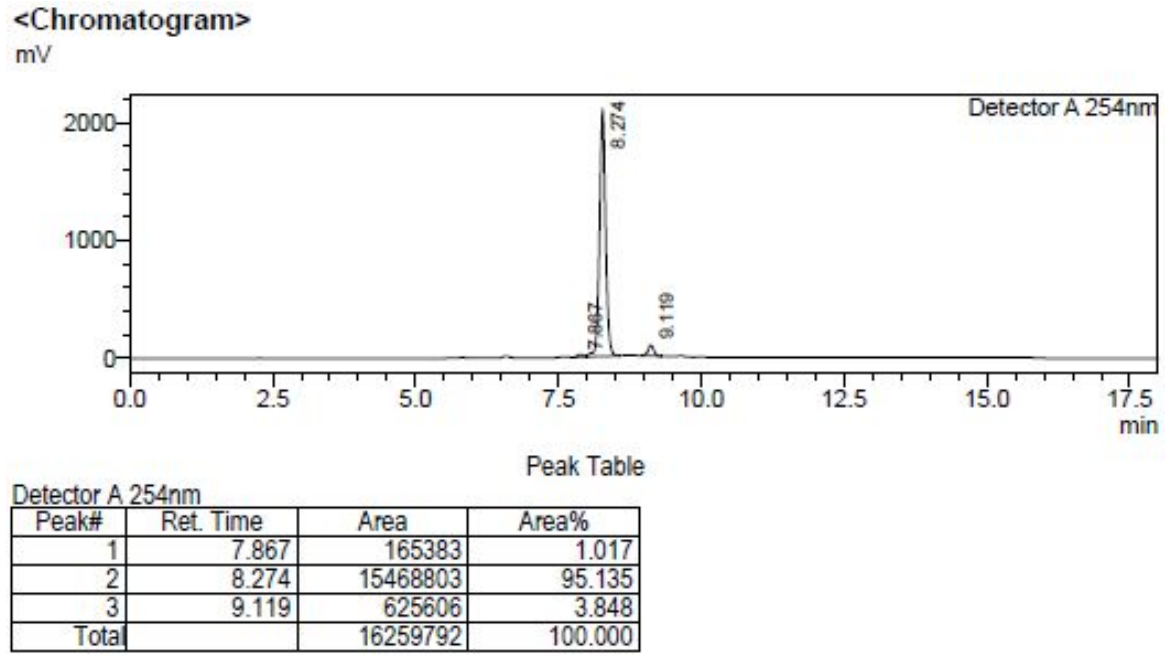

2-(4-Ethoxybenzyl)-N,N-diethyl-1-(2-(2-(2-((1,2,3,4-tetrahydroacridin-9-yl)amino)ethoxy)ethoxy)ethyl)1H-benzo[d]imidazole-5-carboxamide (6.)

Retention time: 7.89 min.; HPLC purity: 99\%

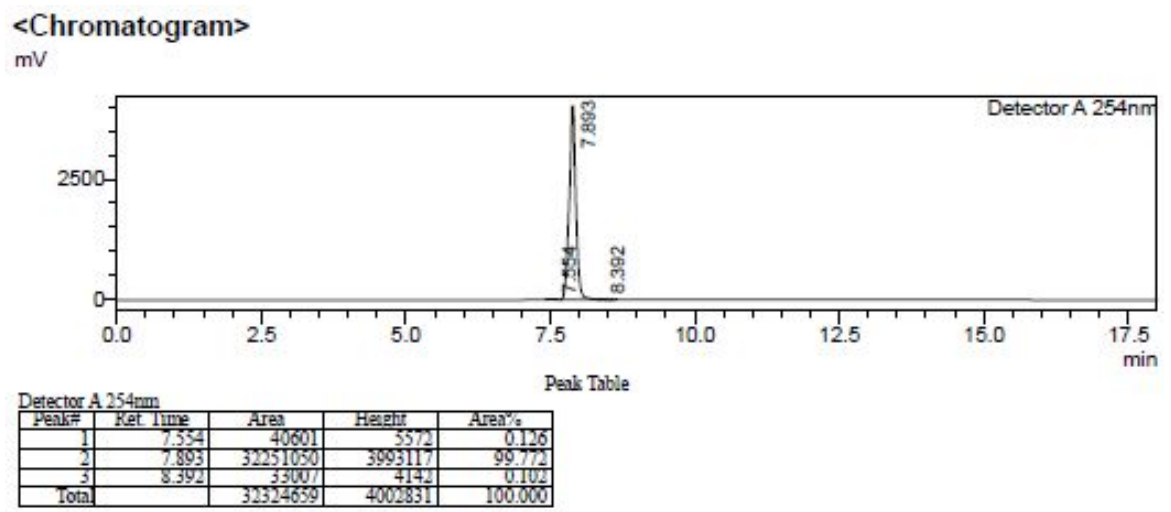


2-(4-Ethoxybenzyl)-1-isopentyl-N-(2-((1,2,3,4-tetrahydroacridin-9-yl)amino)ethyl)-1Hbenzo[d]imidazole-5-carboxamide (4a).

Retention time: 8.96 min.; HPLC purity: 96\%

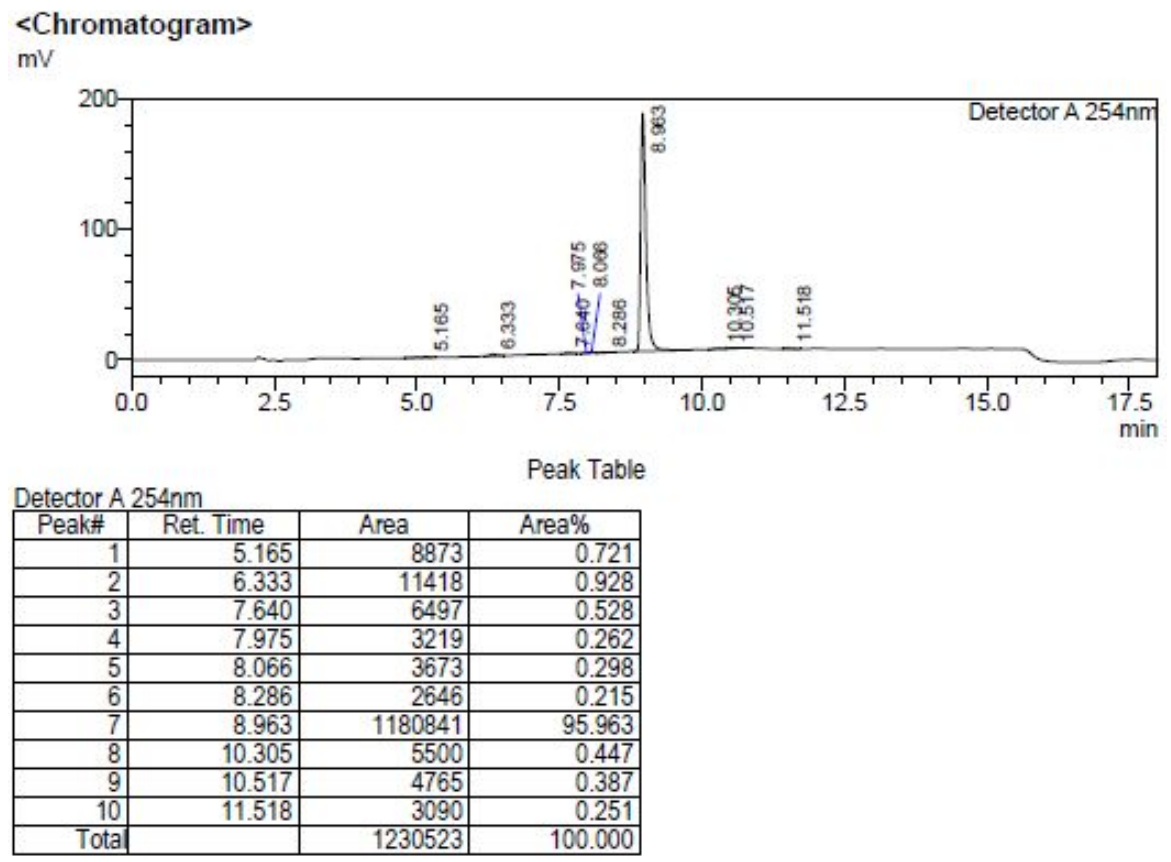

2-(4-Ethoxybenzyl)-1-isopentyl-N-(3-((1,2,3,4-tetrahydroacridin-9-yl)amino)propyl)-1Hbenzo[d]imidazole-5-carboxamide (4b).

Retention time: 8.82 min.; HPLC purity: 98\%

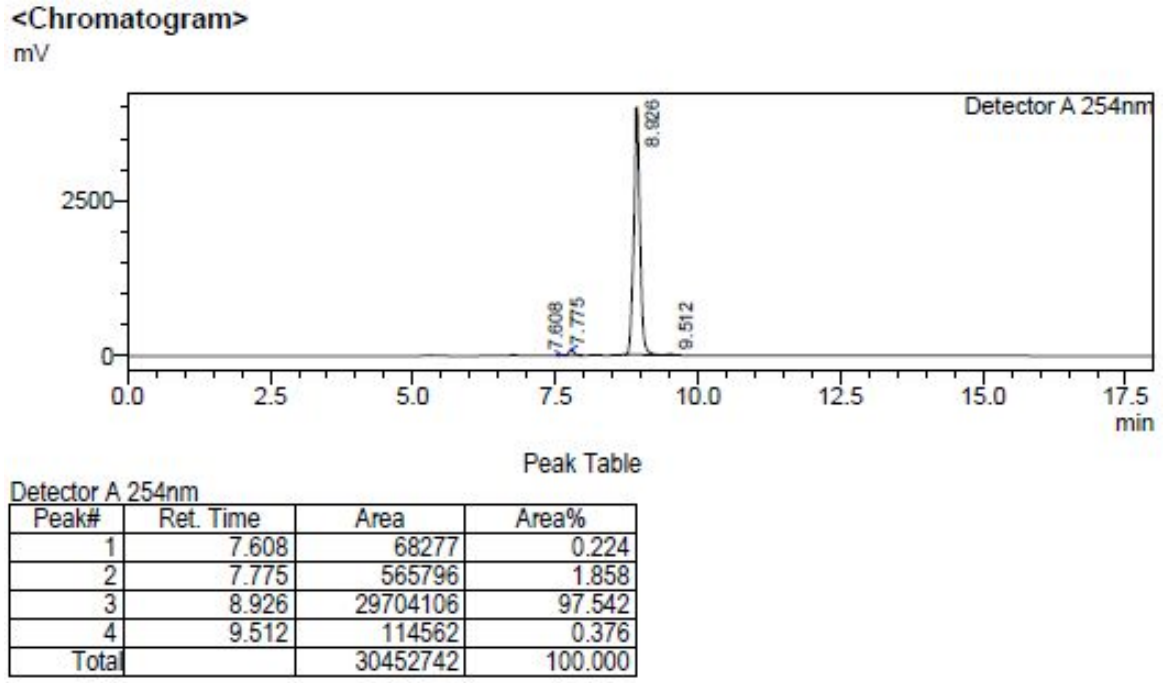


2-(4-Ethoxybenzyl)-1-isopentyl-N-(4-((1,2,3,4-tetrahydroacridin-9-yl)amino)butyl)-1Hbenzo[d]imidazole-5-carboxamide (4c)

Retention time: 8.77 min.; HPLC purity: 98\%

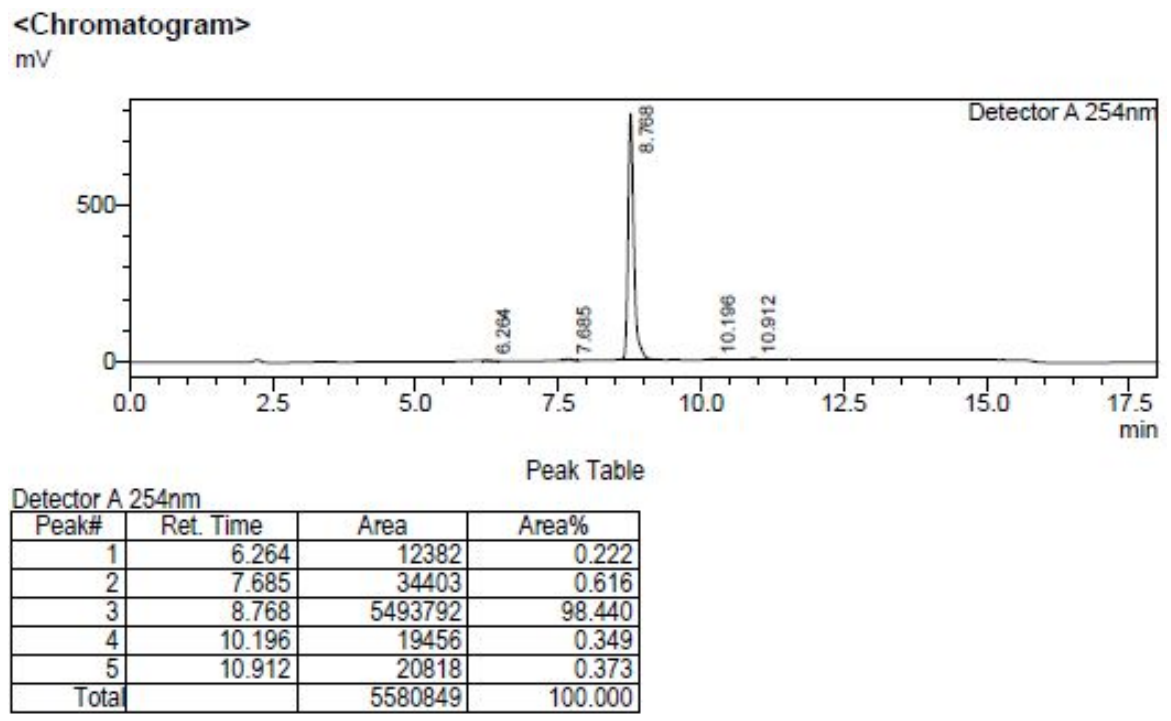

2-(4-Ethoxybenzyl)-1-isopentyl-N-(5-((1,2,3,4-tetrahydroacridin-9-yl)amino)pentyl)-1Hbenzo[d]imidazole-5-carboxamide (4d).

Retention time: 8.82 min.; HPLC purity: 98\%

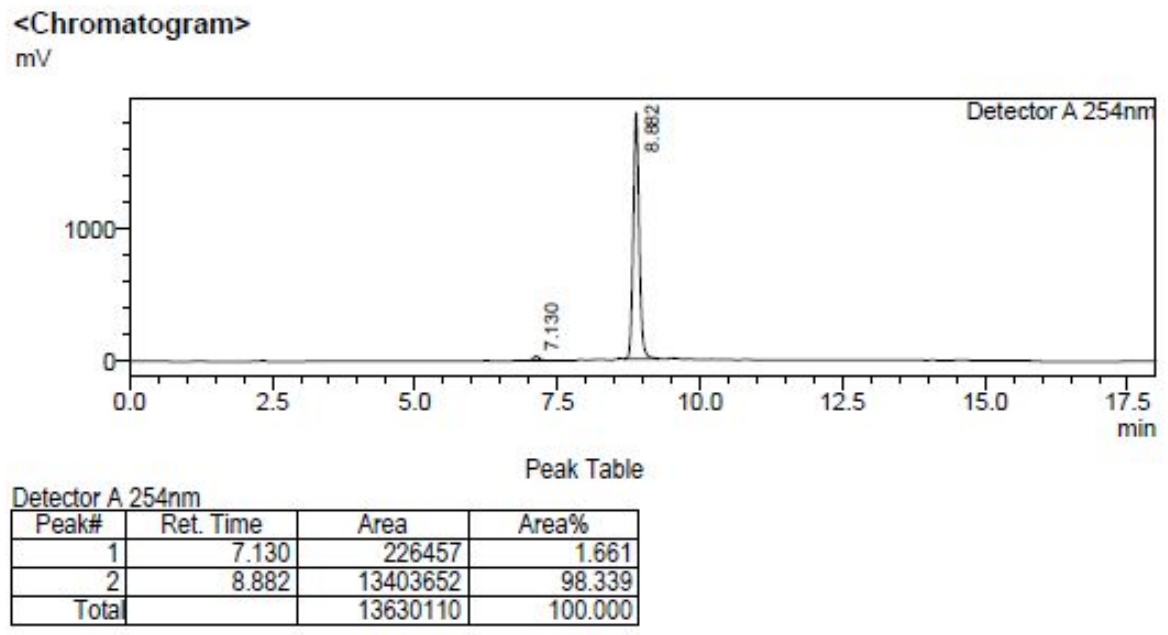


2-(4-Ethoxybenzyl)-1-isopentyl-N-(6-((1,2,3,4-tetrahydroacridin-9-yl)amino)hexyl)-1Hbenzo[d]imidazole-5-carboxamide (4e).

Retention time: 8.94 min.; HPLC purity: 95\%

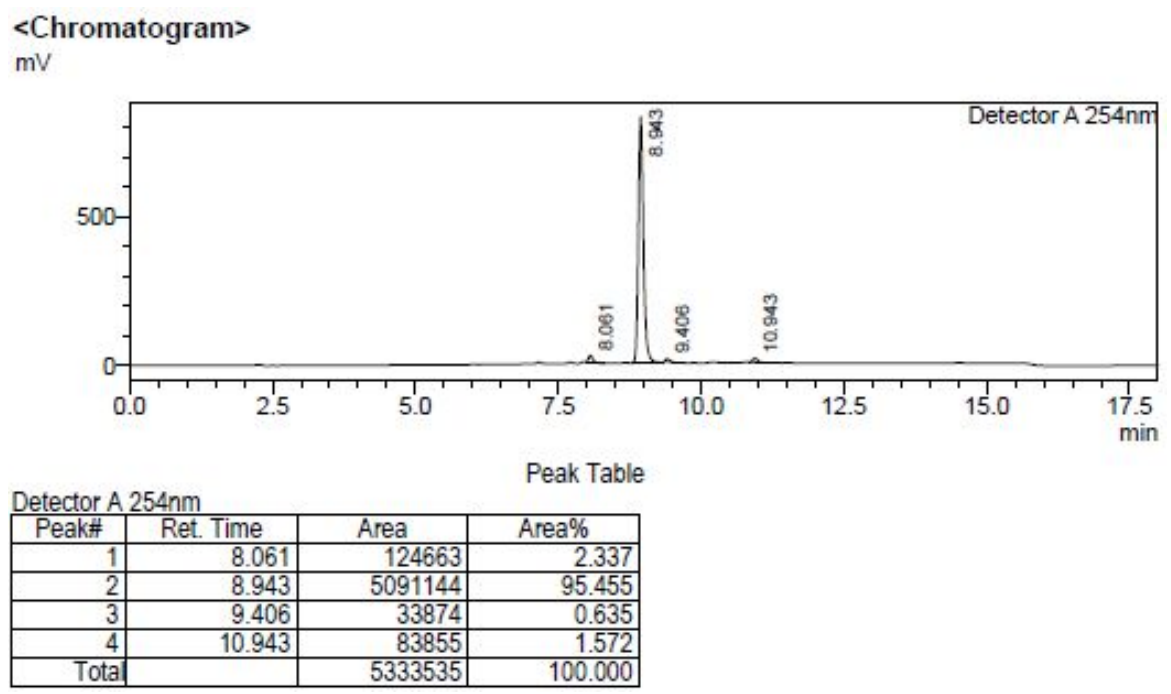

2-(4-ethoxybenzyl)-N-ethyl-1-isopentyl-N-(4-((1,2,3,4-tetrahydroacridin-9-yl)amino)butyl)-1Hbenzo[d]imidazole-5-carboxamide (5).

Retention time:.94 min.; HPLC purity: 99\%

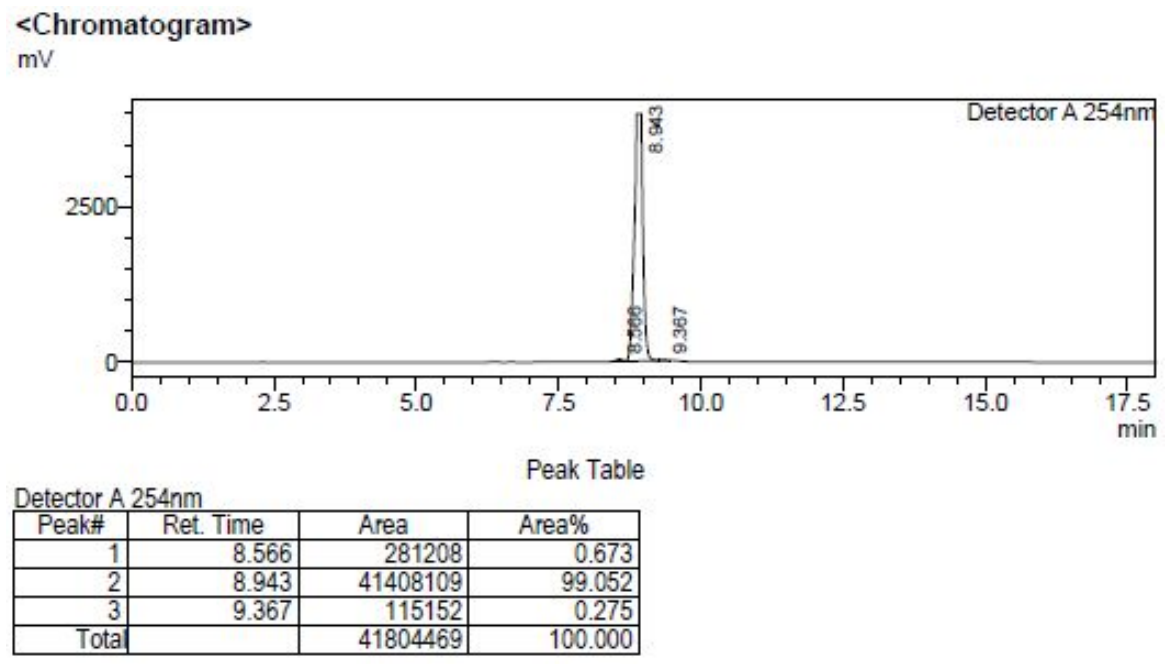


2-(4-Ethoxybenzyl)-1-isopentyl- $N$-(2-(2-(2-((1,2,3,4-tetrahydroacridin-9-yl)amino)ethoxy)ethoxy)ethyl)$1 H$-benzo[d]imidazole-5-carboxamide (7)

Retention time: 8.75 min.; HPLC purity: 98\%

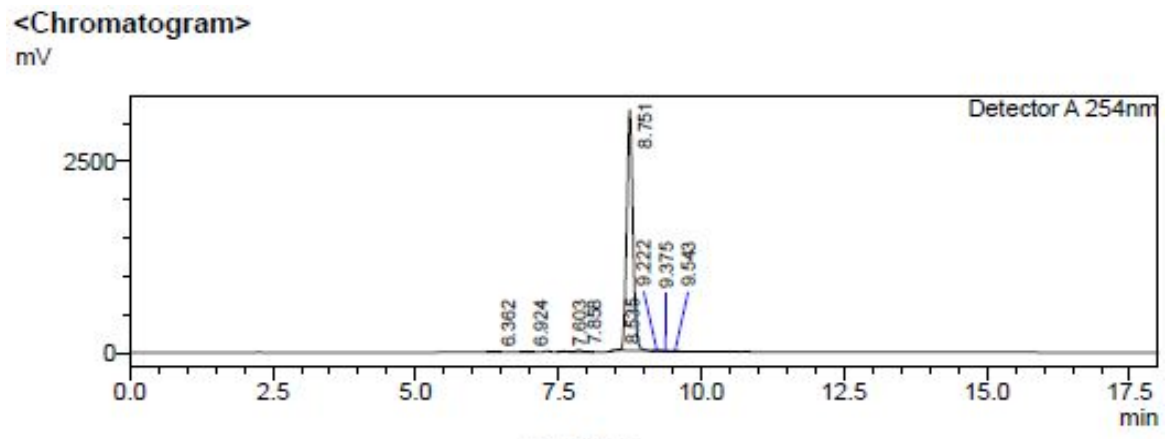

Peak Table

Detector A $254 n m$
\begin{tabular}{|r|r|r|r|}
\hline \multicolumn{1}{|c|}{ Peak\# } & Ret. Time & \multicolumn{1}{c|}{ Area } & \multicolumn{1}{c|}{ Area\% } \\
\hline 1 & 6.362 & 19310 & 0.081 \\
\hline 2 & 6.924 & 17679 & 0.074 \\
\hline 3 & 7.603 & 64564 & 0.269 \\
\hline 4 & 7.858 & 203467 & 0.848 \\
\hline 5 & 8.535 & 53973 & 0.225 \\
\hline 6 & 8.751 & 23438596 & 97.741 \\
\hline 7 & 9.222 & 75738 & 0.316 \\
\hline 8 & 9.375 & 9213 & 0.038 \\
\hline 9 & 9.543 & 97812 & 0.408 \\
\hline Tota & & 23980352 & 100.000 \\
\hline
\end{tabular}

2-(4-Ethoxybenzyl)-1-isopentyl-N-(2-((2-((1,2,3,4-tetrahydroacridin-9-yl)amino)ethyl)disulfaneyl)ethyl)1H-benzo[d]imidazole-5-carboxamide (8).

Retention time: 9.38 min.; HPLC purity: 96\%

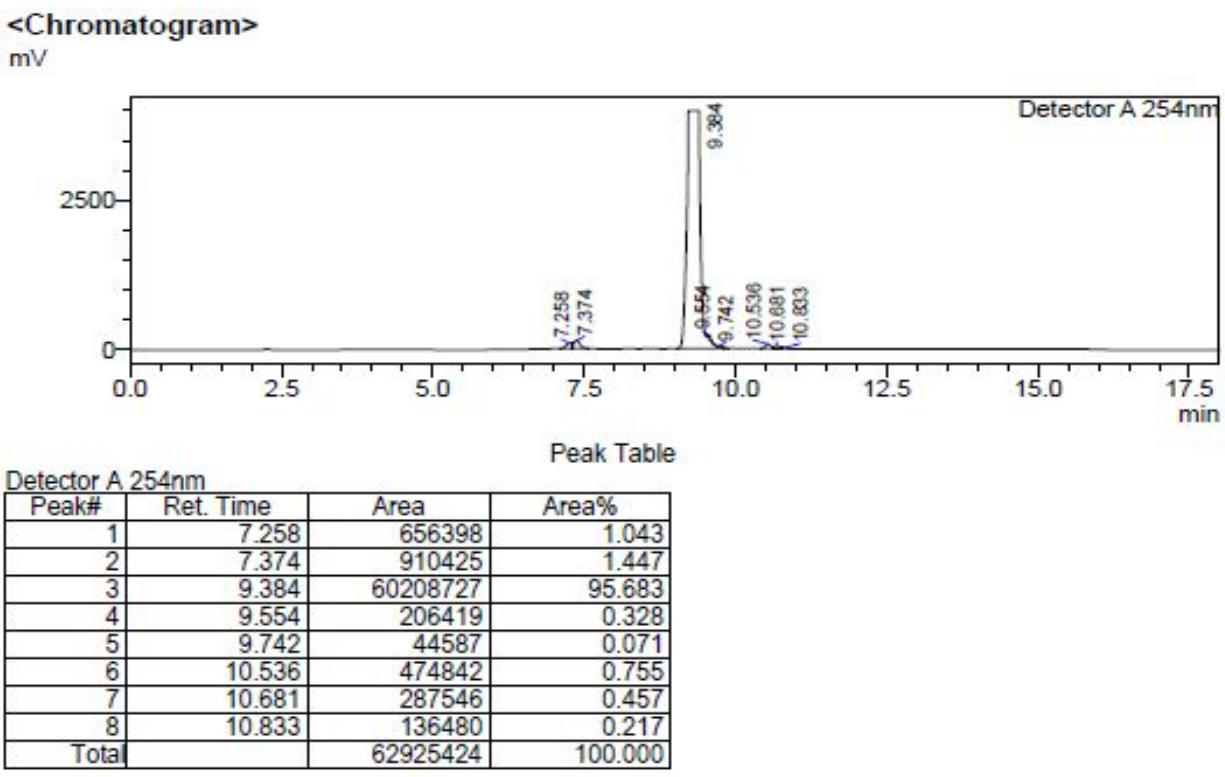




\section{Pharmacology}

\section{$\mu O R$ Binding studies}

Binding affinities towards the human $\mu \mathrm{OR}$ were determined as described previously. ${ }^{1,2}$ In brief, membranes were prepared from HEK293T cells each transiently transfected with the cDNAs for $\mu \mathrm{OR}$ (generous gift from the Ernest Gallo Clinic and Research Center, UCSF, CA). Receptor density ( $B_{\max }$ value) and specific binding $\left(K_{D}\right.$ value) for the radioligand $\left[{ }^{3} \mathrm{H}\right]$ diprenorphine (specific activity $31 \mathrm{Ci} / \mathrm{mmol}$, PerkinElmer, Rodgau, Germany) were determined as $2000 \mathrm{fmol} / \mathrm{mg}$ protein and $0.08 \mathrm{nM}$, respectively. Competition binding experiments were performed by incubating membranes in binding buffer ( $50 \mathrm{mM}$ Tris, $5 \mathrm{mM} \mathrm{MgCl}_{2}$, $0.1 \mathrm{mM}$ EDTA, $5 \mu \mathrm{g} / \mathrm{mL}$ bacitracin and $5 \mu \mathrm{g} / \mathrm{mL}$ soybean trypsin inhibitor at $\mathrm{pH} 7.4$ ) at a final protein concentration of $4 \mu \mathrm{g} / \mathrm{well}$, together with the radioligand (final concentration $0.3 \mathrm{nM}$ ) and varying concentrations of the competing ligands for 60 minutes at $37^{\circ} \mathrm{C}$. Non-specific binding was determined in the presence of naloxone at a final concentration of $10 \mu \mathrm{M}$. The protein concentration was established using the method of Lowry. ${ }^{3}$ The resulting competition curves were analyzed by nonlinear regression using the algorithms implemented using GraphPad Prism software, to provide an $\mathrm{IC}_{50}$ value, which was subsequently transformed into the $K_{i}$ value employing the equation of Cheng and Prusoff. ${ }^{4}$

Supplementary Table 1. Receptor binding data of the test compounds $\mathbf{x}-\mathbf{x}$ to the $\mu \mathrm{OR}$ opioid receptor.

\begin{tabular}{cc}
\hline & Ki value $^{[a]}[\mathrm{nM} \pm$ SEM $]$ \\
\hline ligand & $\mu \mathrm{OR}$ \\
\hline 4e & $410 \pm 67$ \\
3a & $220 \pm 77$ \\
4a & $280 \pm 93$
\end{tabular}

${ }^{[a]} \mathrm{K}_{\mathrm{i}}$ values in $[\mathrm{nM} \pm \mathrm{SEM}]$ are the means of three individual experiments each done in triplicate.

\section{$h \mathrm{CB}_{2} \mathrm{R}$ Efficacy: MTT assay}

The U266 cell line ( 4 x 104 cells $/ \mathrm{mL}$ ) was plated on 96-well plates, to a final volume of $100 \mu \mathrm{L} /$ well. After incubating for one day, compounds or vehicles were added at different concentration. Six replicates were used for each treatment. At the indicated time point, cell viability was assessed by adding $0.8 \mathrm{mg} / \mathrm{mL}$ of 3 [4,5-dimethylthiazol- 2-yl]-2,5 diphenyl tetrazolium bromide (MTT) (Sigma Aldrich) to the medium. After $3 \mathrm{~h}$, the plates were centrifuged, the supernatant discarded and the pellet solubilized with $100 \mu \mathrm{L} /$ well 
DMSO. The absorbance of the samples against a background control (medium alone) was measured at 570 nm using an ELISA reader microliter plate (BioTek Instruments, Winooski, VT, USA). For some experiments, one hour of pre-incubation with Forskolin or AM630 was performed. Each sample was evaluated in six wells and in two independent experiments.
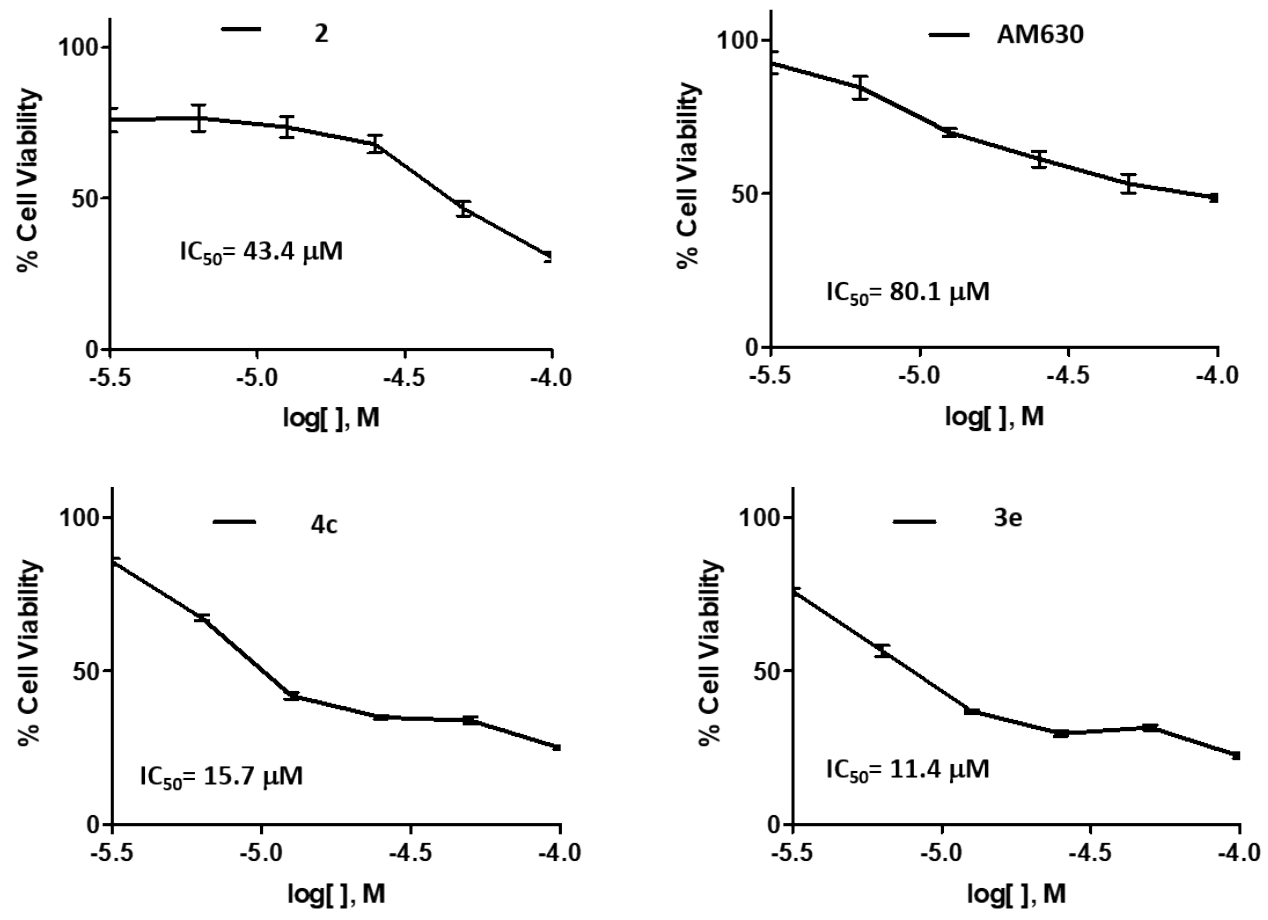

Supplementary Figure 1. Test compounds (2, AM630, 4c and 3e) effect on U266 cell viability. U266 cells were treated with different doses of test compounds or AM630 (from 0 to $100 \mu \mathrm{M}$ ) and cell viability was evaluated at $72 \mathrm{~h}$ post- treatments, by MTT assay. Data shown are expressed as mean \pm S.D. of three independent experiments. $\mathrm{IC}_{50}$ values of test compounds and $\mathrm{AM} 630$ are indicated. Each compound was tested in six wells/experiment. 


\begin{tabular}{c|cccc} 
& MIF & STAT-3 & MIF S.D. & STAT-3 S.D. \\
\hline VEI & 1 & 1 & $\pm 0,11$ & $\pm 0,09$ \\
FSK & 8,3 & 3,4 & $\pm 0,41$ & $\pm 0,17$ \\
AM630 & 3,8 & 2,2 & $\pm 0,17$ & $\pm 0,14$ \\
2 & 0,33 & 0,45 & $\pm 0,04$ & $\pm 0,02$ \\
3e & 0,28 & 0,25 & $\pm 0,02$ & $\pm 0,02$ \\
$4 \mathrm{c}$ & 0,23 & 0,52 & $\pm 0,02$ & $\pm 0,01$ \\
AM630 & 1,6 & 1,8 & $\pm 0,01$ & $\pm 0,01$ \\
AM630 $+3 \mathrm{e}$ & 1,4 & 1,6 & $\pm 0,01$ & $\pm 0,01$ \\
AM630 $+4 \mathrm{c}$ & 0,82 & 1,12 & $\pm 0,01$ & $\pm 0,01$
\end{tabular}

Supplementary Figure 2. The effect of test compounds on AM630-induced stimulation of cAMP production in U266 cells. 4 x 104U266 cells were plated in 24 well plates and treated for 24 hours with the appropriate compound. In combination treatments, U266 cells were pre-incubated with $25 \mu \mathrm{M}$ AM630 for 30 minutes before adding test compounds. U266 cell lines were treated with forskolin (10 $\mu \mathrm{M})$, AM630 (25 $\mu \mathrm{M})$, test compounds $(50 \mu \mathrm{M})$. cAMP concentration was represented as picograms for $\mathrm{mg}$ of protein ( $\mathrm{pg} / \mathrm{mg}$ ). * indicate any values that are significantly different from vehicle treated cells $(* * \mathrm{P}<0.01)$, \# ${ }^{\circ}$ indicate any values that are significantly different from AM630 treated cells $(* * \mathrm{P}<0.01)$. Values represent the mean \pm S.D. $(n=4)$ calculated from two wells/treatment and in two independent experiments.

\section{Neuroprotection on HT-22 cells}
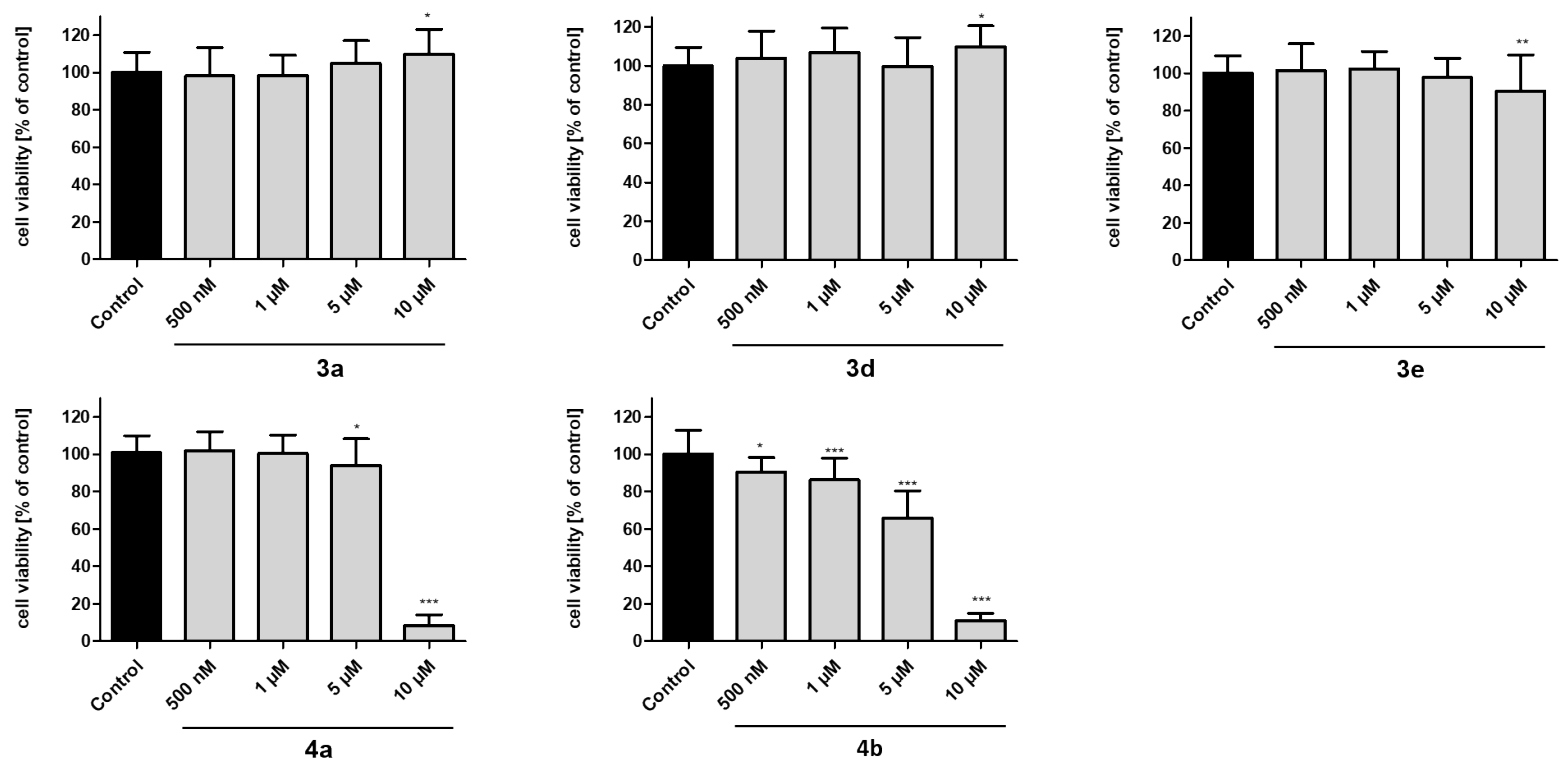


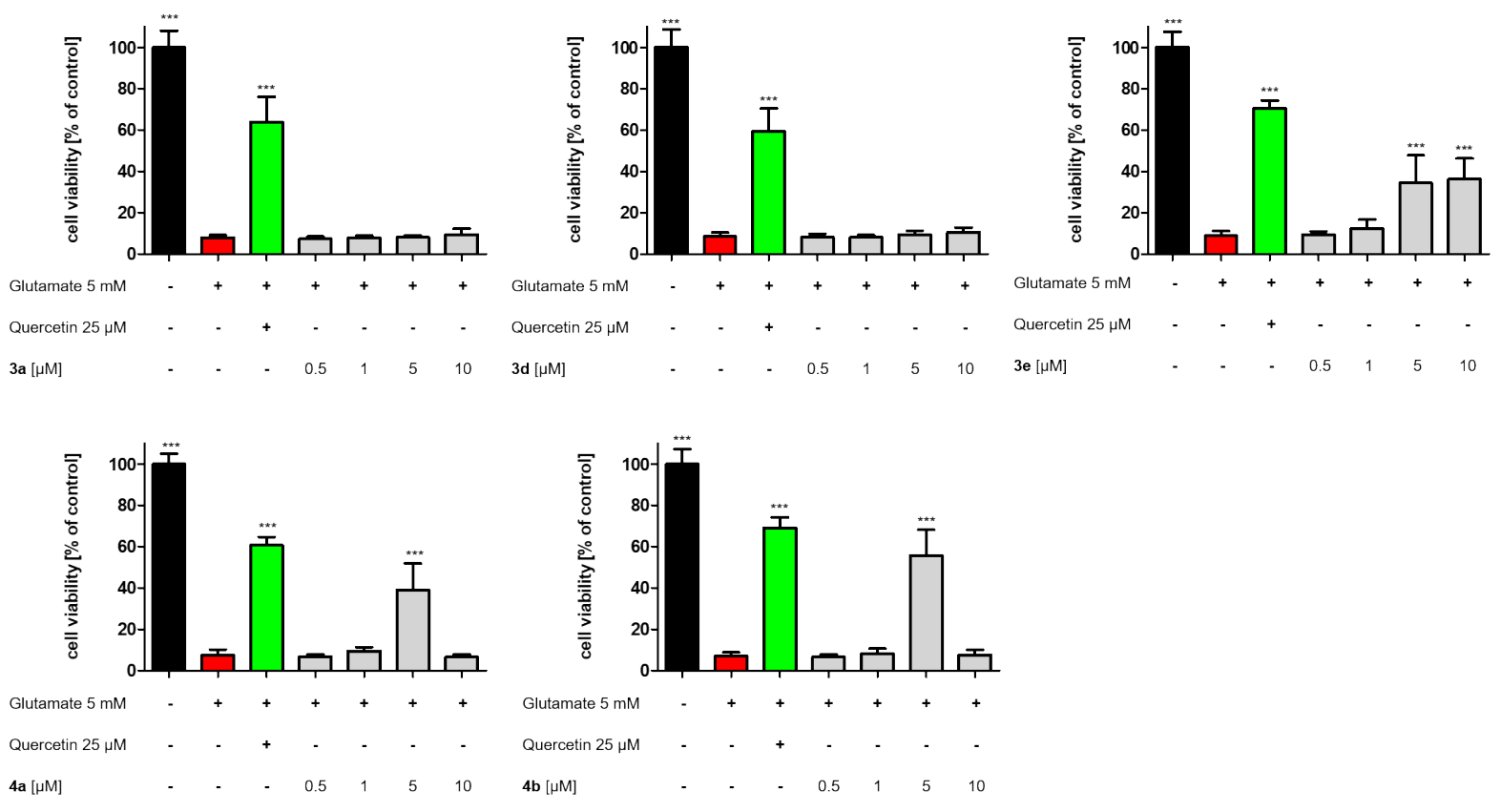

Supplementary Figure 3. Compound 3a, 3d, 3e, 4a and $\mathbf{4 b}$ were studied on neuronal HT-22 cells for $(A)$ neurotoxic effects and $(B+C)$ neuroprotection against glutamate induced oxidative stress at $0.5-10 \mu \mathrm{M}$. Results of the modified MTT test are presented as means \pm SD of three different independent experiments and refer to untreated control cells which were set as $100 \%$ values. Statistical analysis was achieved by applying one-way ANOVA followed by Dunnett's multiple comparison post-test. Levels of significance: ${ }^{*} \mathrm{p}<0.005 ;{ }^{* *} \mathrm{p}<0.01 ; * * \mathrm{p}<0.001$. Treated cells were compared to (A) untreated cells and (B) cells treated with glutamate only. Assay was performed in three independent experiments, each performed in sextuplicate. 


\section{In Vivo Studies}

\section{Weight}
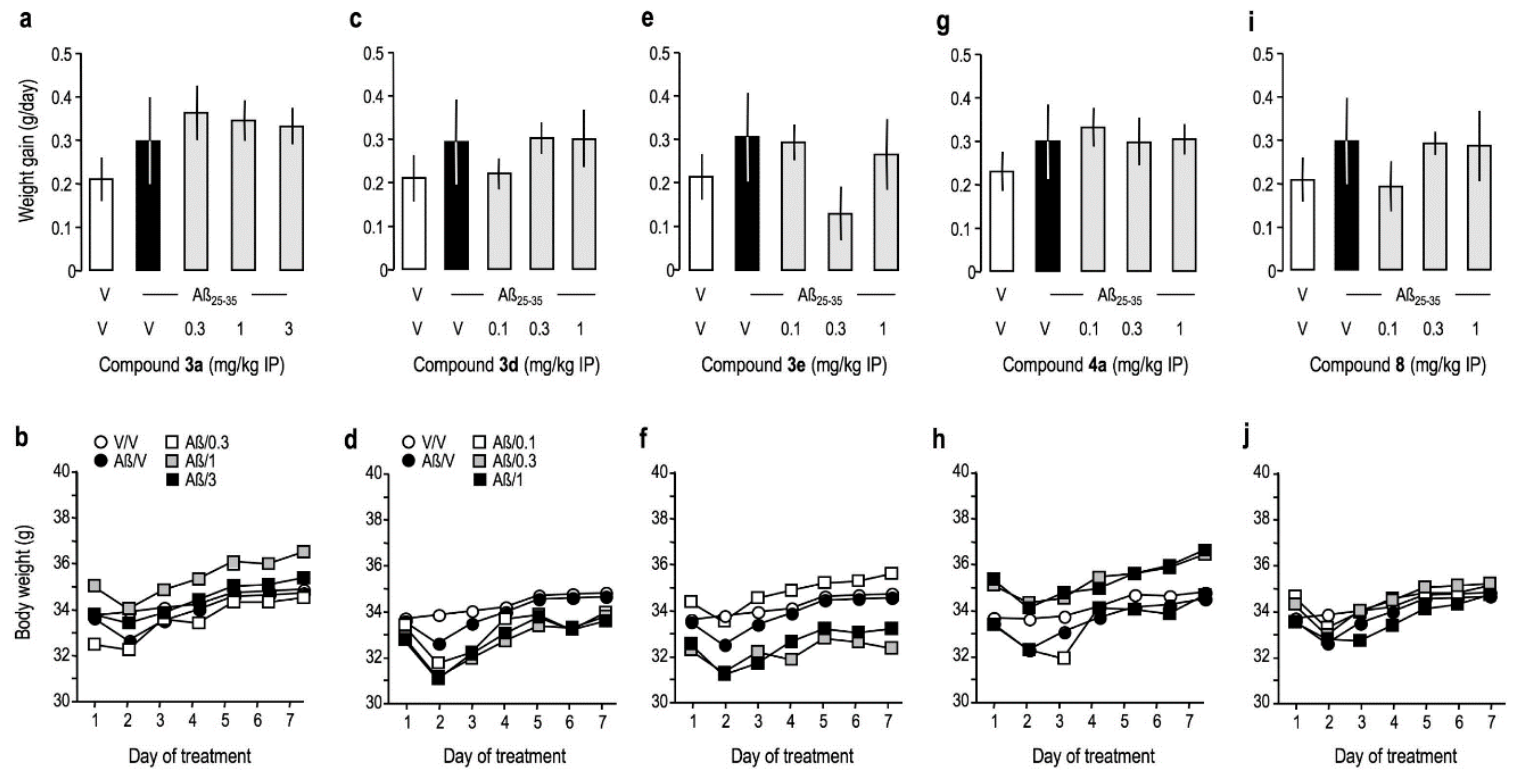

Supplementary Figure 4. Mouse body weight during the 7 days repeated treatment with the compounds 3a $(a, b), \mathbf{3 d}(\mathrm{c}, \mathrm{d}), \mathbf{3 e}(\mathrm{e}, \mathrm{f}), \mathbf{4 a}(\mathrm{g}, \mathrm{h}), \mathbf{8}(\mathrm{I}, \mathrm{j})$ : average daily weight gain (upper panels) and daily weight measure (lower panel) for each treatment group. Note that $A \beta_{25-35}$ peptide ICV injection on day 1 provoked a slight weight decrease, but all groups then gradually regain weight normally, whatever the treatment. ANOVA: $F_{(4,80)}=0.970, \mathrm{p}>0.05$ in (a); $F_{(4,67)}=0.538, \mathrm{p}>0.05$ in $(\mathrm{c}) ; F_{(4,69)}=0.891, \mathrm{p}>0.05$ in (e); $F_{(4,74)}=0.419, \mathrm{p}$ $>0.05$ in $(\mathrm{g}) ; F_{(4,69)}=0.513, \mathrm{p}>0.05$ in (i). 


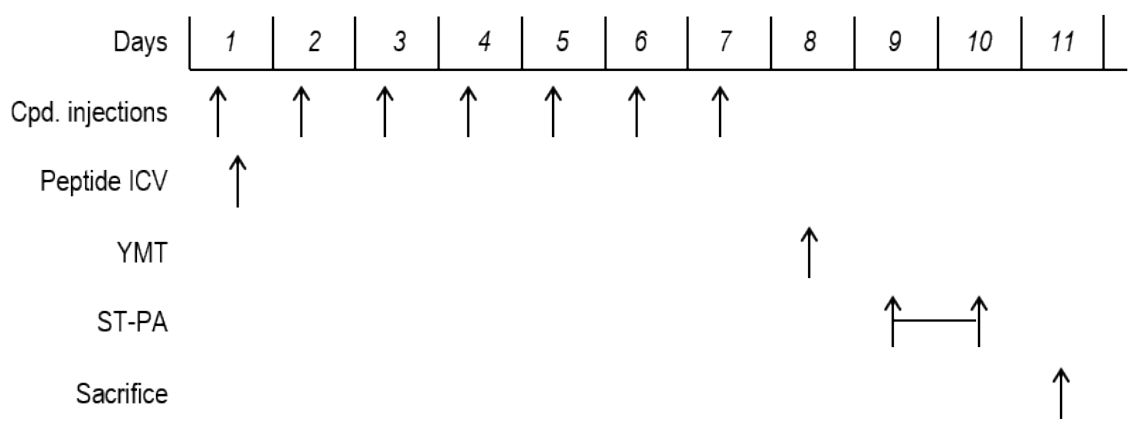

Supplementary Figure 5. Protocol followed. Abbreviations: Cpd. Compound; ICV,

intracerebroventricular injection; YMT, spontaneous alternation test in the Y-maze; ST-

PA, step-through passive avoidance test.

\section{References}

1. Hübner, H.; Haubmann, C.; Utz, W.; Gmeiner, P. Conjugated enynes as nonaromatic catechol bioisosteres: synthesis, binding experiments, and computational studies of novel dopamine receptor agonists recognizing preferentially the D3 subtype. J. Med. Chem. 2000, 43 (4), 756-762.

2. $\quad$ Fish, I.; Stößel, A.; Eitel, K.; Valant, C.; Albold, S.; Huebner, H.; Möller, D.; Clark, M. J.; Sunahara, R. K.; Christopoulos, A. Structure-based design and discovery of new M2 receptor agonists. J. Med. Chem. 2017, 60 (22), 9239-9250.

3. Lowry, O. H.; Rosebrough, N. J.; Farr, A. L.; Randall, R. J. Protein measurement with the Folin phenol reagent. J. Biol. Chem. 1951, 193, 265-275.

4. Cheng,, Y.; Prusoff, W. H. Relationship between the inhibition constant (KI) and the concentration of inhibitor which causes 50 per cent inhibition (I50) of an enzymatic reaction. Biochem. Pharmacol. 1973, 22 (23), 3099-3108. 